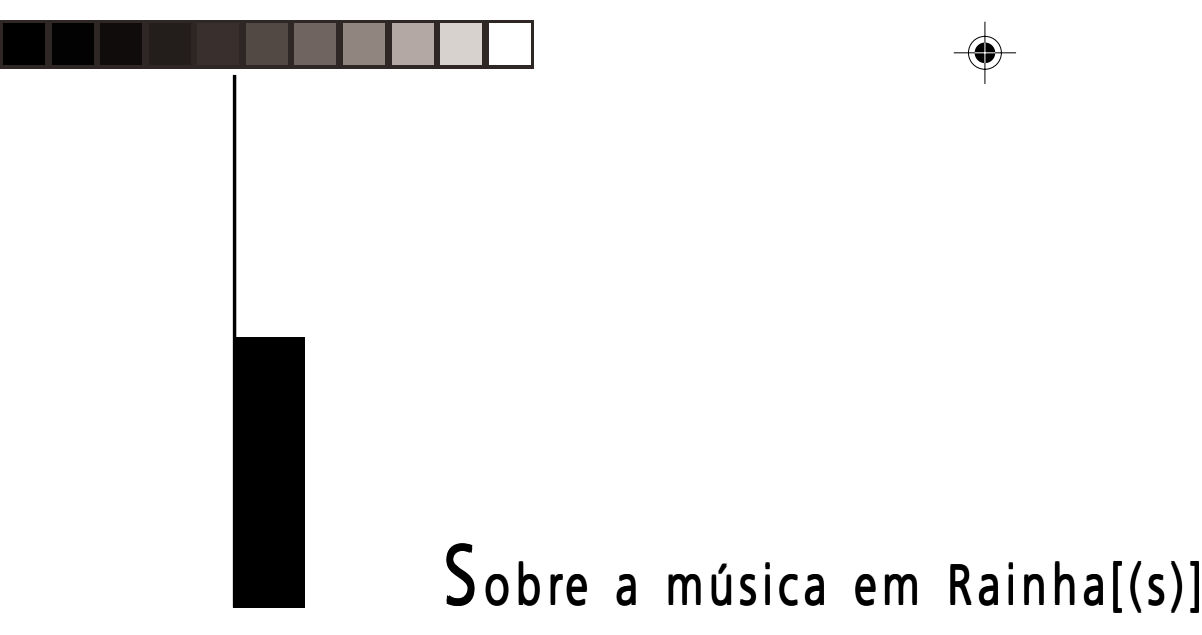

Lincoln Antonio

música de Rainha[(s)] é composta de nove canções e quatro temas instrumentais. Duas vozes, um piano e um trompete executam a música ao vivo. As canções são mais fechadas como forma, mas seu acompanhamento e os temas instrumentais são bem livres, bastante improvisados em certos momentos. Foi esse o motivo que nos levou a publicar as partituras apenas com a melodia cifrada, sem indicações do acompanhamento, para não trair o espírito original desta música de cena. É preciso sempre, de alguma maneira, recriá-las. As próprias melodias sugerem seu acompanhamento e são pontos de partida para a performance musical.

As cançōes surgiram primeiramente a partir da tradução de Manuel Bandeira do texto original de Schiller. De poeta para poeta. A tradução de Bandeira é toda metrificada, em decassílabos, mas sem rimas. Embora o verso longo seja menos comum na canção brasileira, a tradução não deixa de revelar a extrema musicalidade de Bandeira, que se expressa no ritmo e nas rimas internas. Foi da experiência de tornar cantável esta tradução - recortando, colando e reeditando os versos - que as primeiras idéias temáticas se consolidaram e acabaram por nortear todo o desenvolvimento musical da peça.
O compositor Walter Garcia colaborou na feitura de parte das cançôes, sobretudo nas duas canções finais que nascem de necessidades dramatúrgicas do espetáculo, já distantes do texto original. Nestas cançóes ecoam as vozes de Hamlet ("onde a alegria mais canta...") e novamente Manuel Bandeira, o poeta de Tema e voltas e Preparação para a morte.

Algumas cançôes de John Dowland, compositor inglês contemporâneo das "rainhas", foram cantadas nos primeiros ensaios como preparação e aquecimento. A atmosfera destas cançôes, carregadas de melancolia e geralmente a duas vozes, também nos serviu como estímulo sonoro e Dowland acabou nos "emprestando" trechos melódicos na canção cantada por Elizabeth no final do $2^{\circ}$ Ato.

Por fim surge a colaboração do compositor Manuel Pessoa, em cena ao piano, acompanhando o canto das atrizes, desenvolvendo e ampliando o material musical, especialmente no $4^{\circ}$ ato onde toda a cena da segunda votação transcorre através de sua improvisação.

Aí está a música de Rainha[(s)], resultado da colaboração entre três compositores em conjunto com o elenco e direção para a construção de uma música de cena em parte composta, em parte improvisada.

Lincoln Antônio é músico. 
TEMA DO CORAÇÃO

Lincoln Antonio
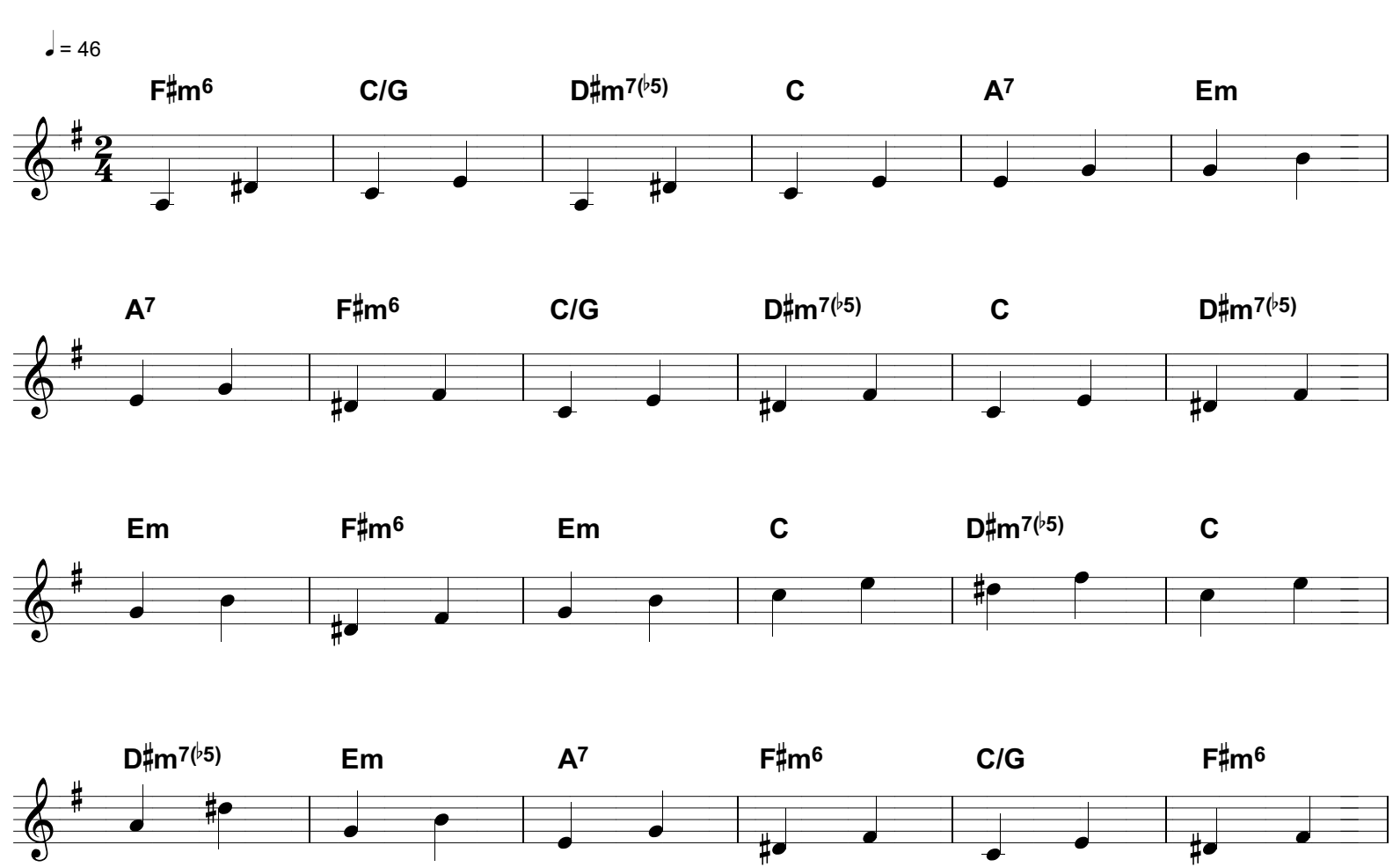

(๑)

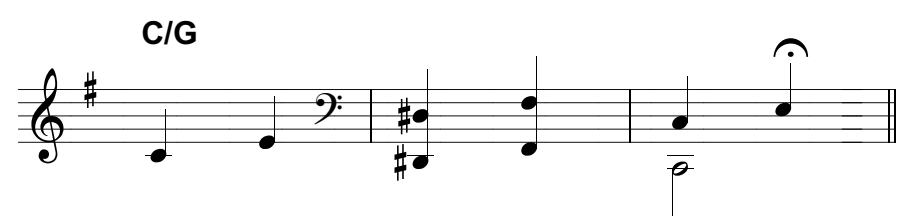

174 
Sobre a música em Rainha[(s)]

\section{ERREI SIM}
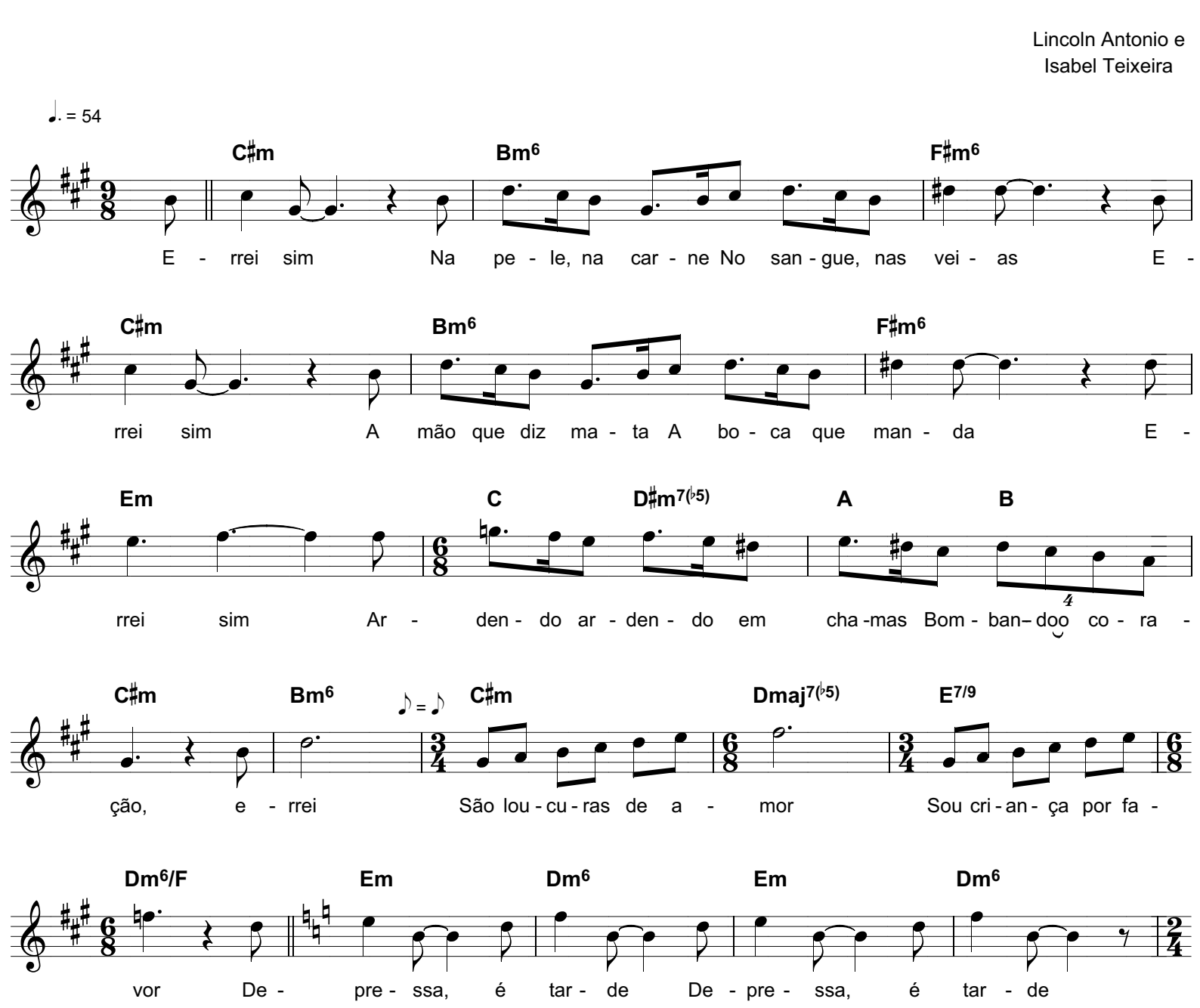


\section{CONDENADA}

Lincoln Antonio
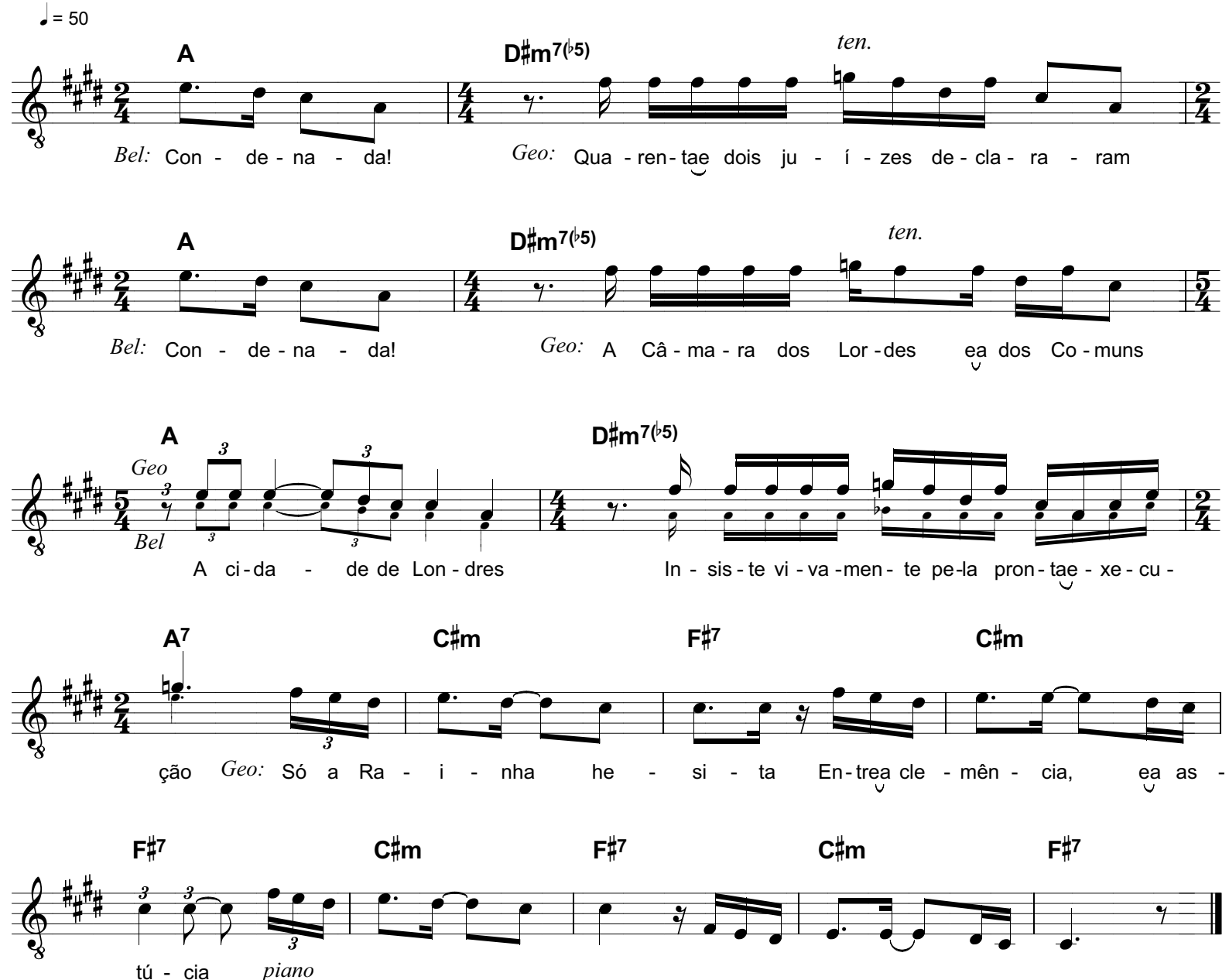

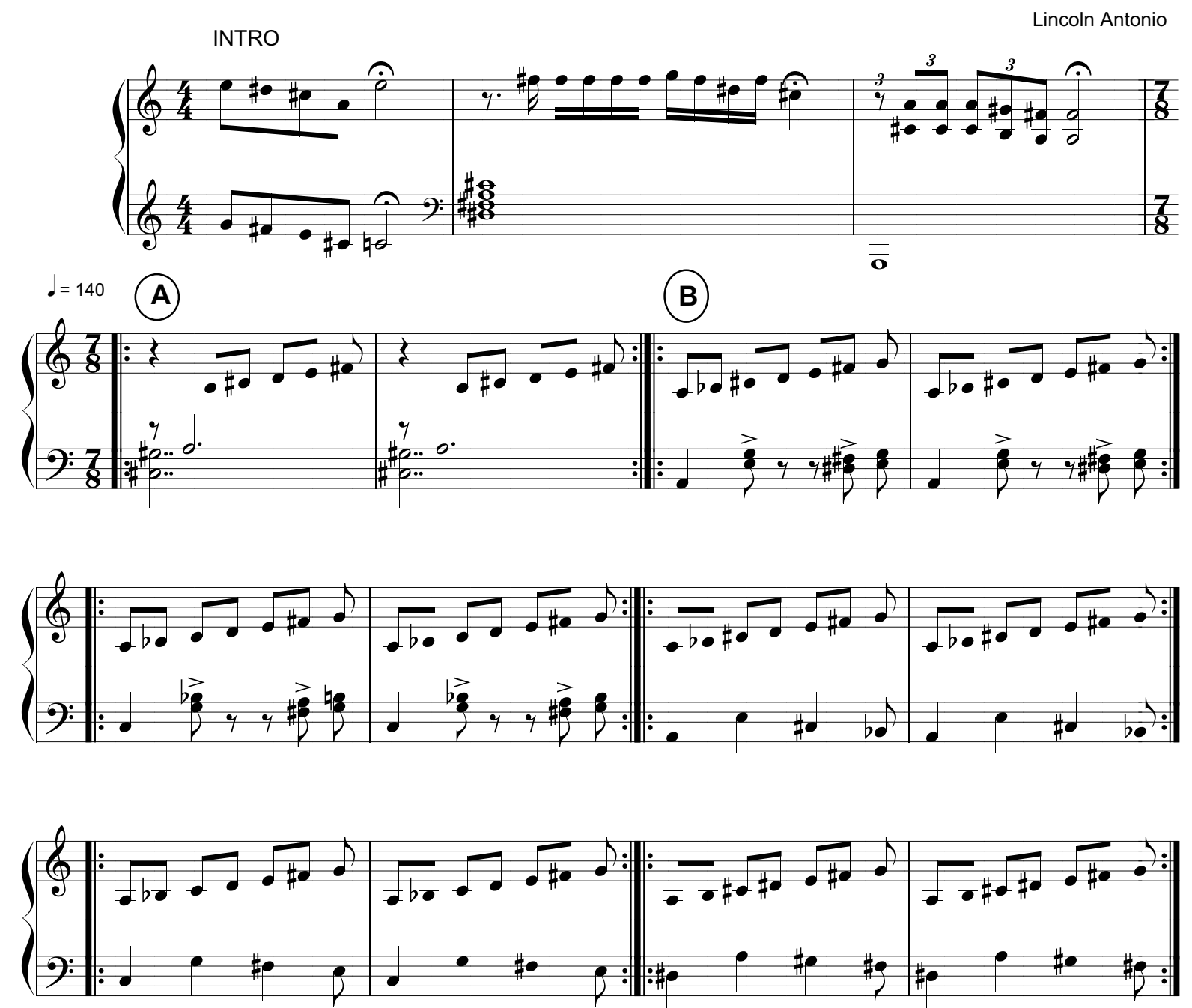

(c)
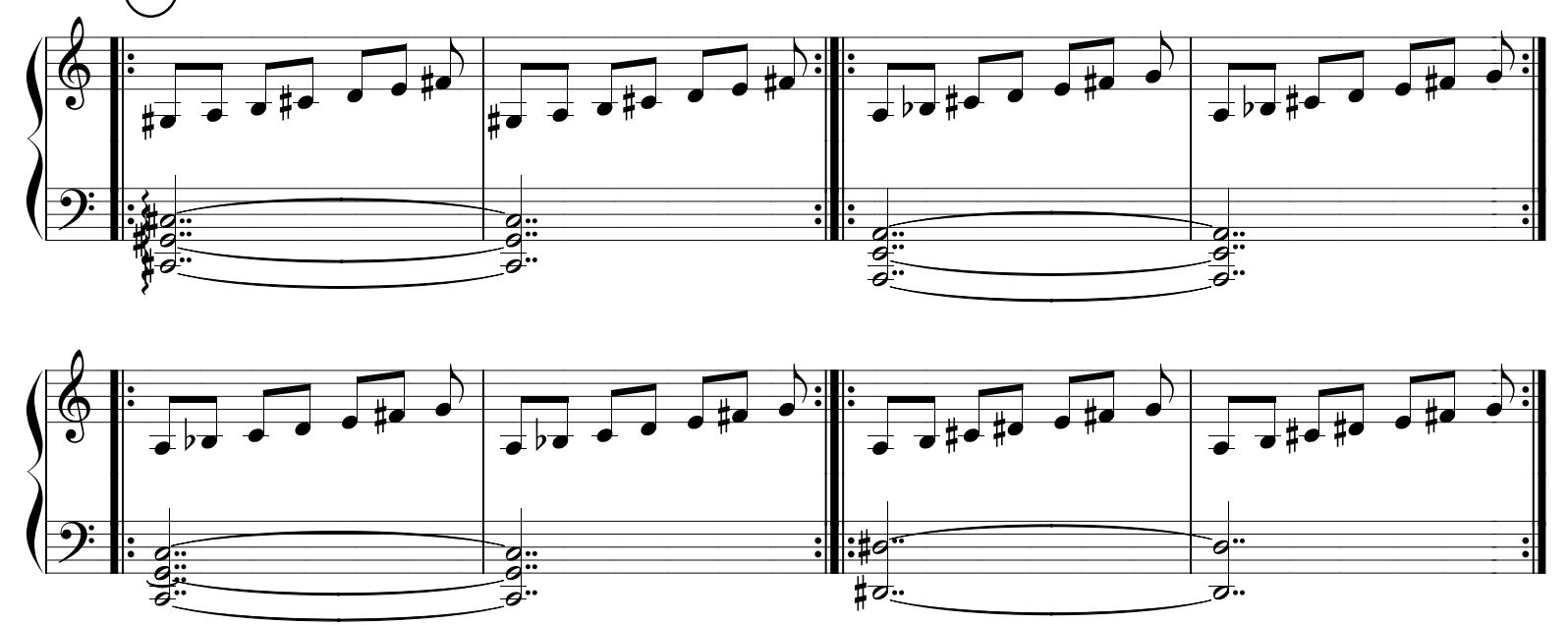
AUDÁCIA
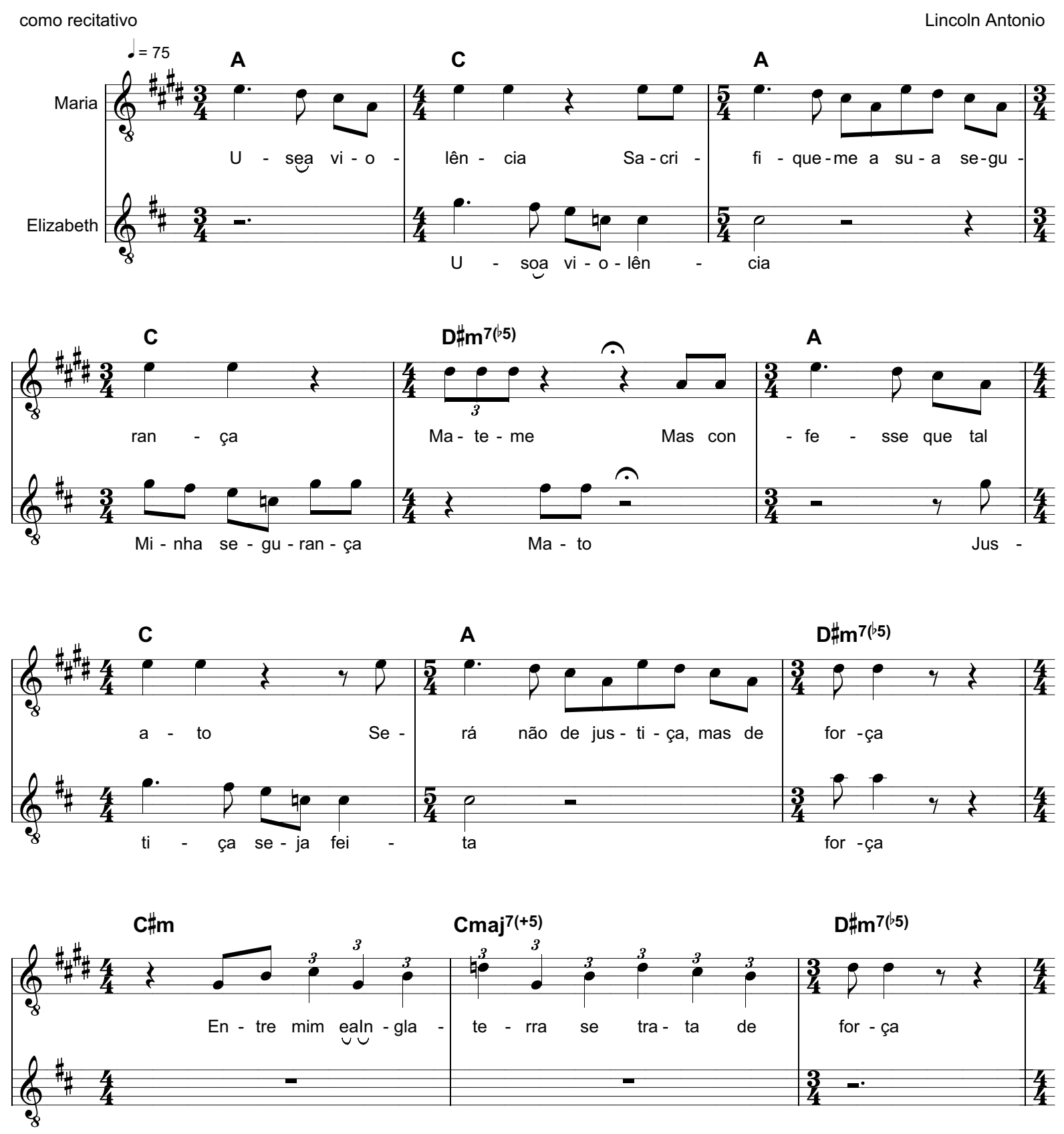

178 
MARY, ME ?
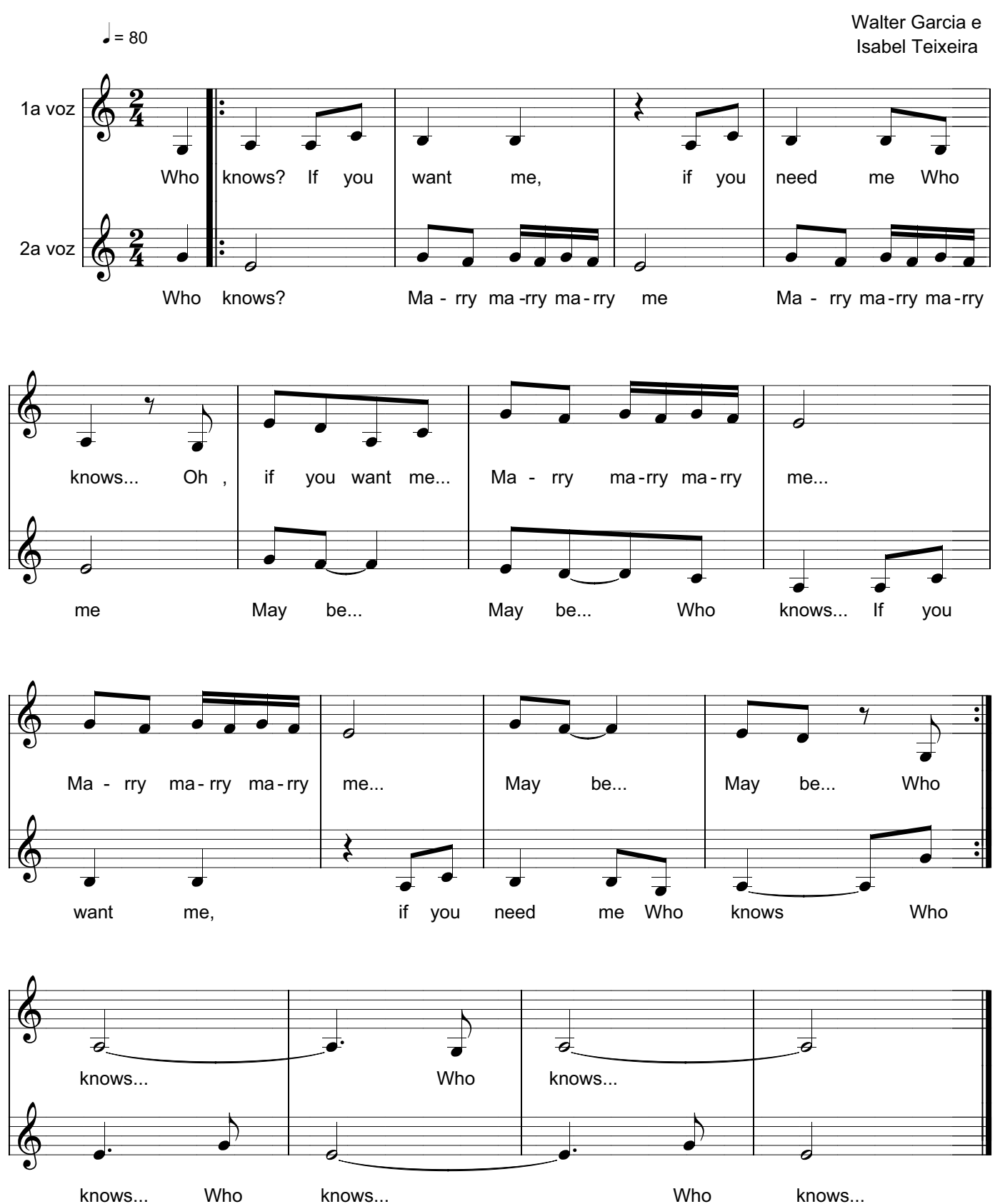


\section{QUE POUCO É O HOMEM}
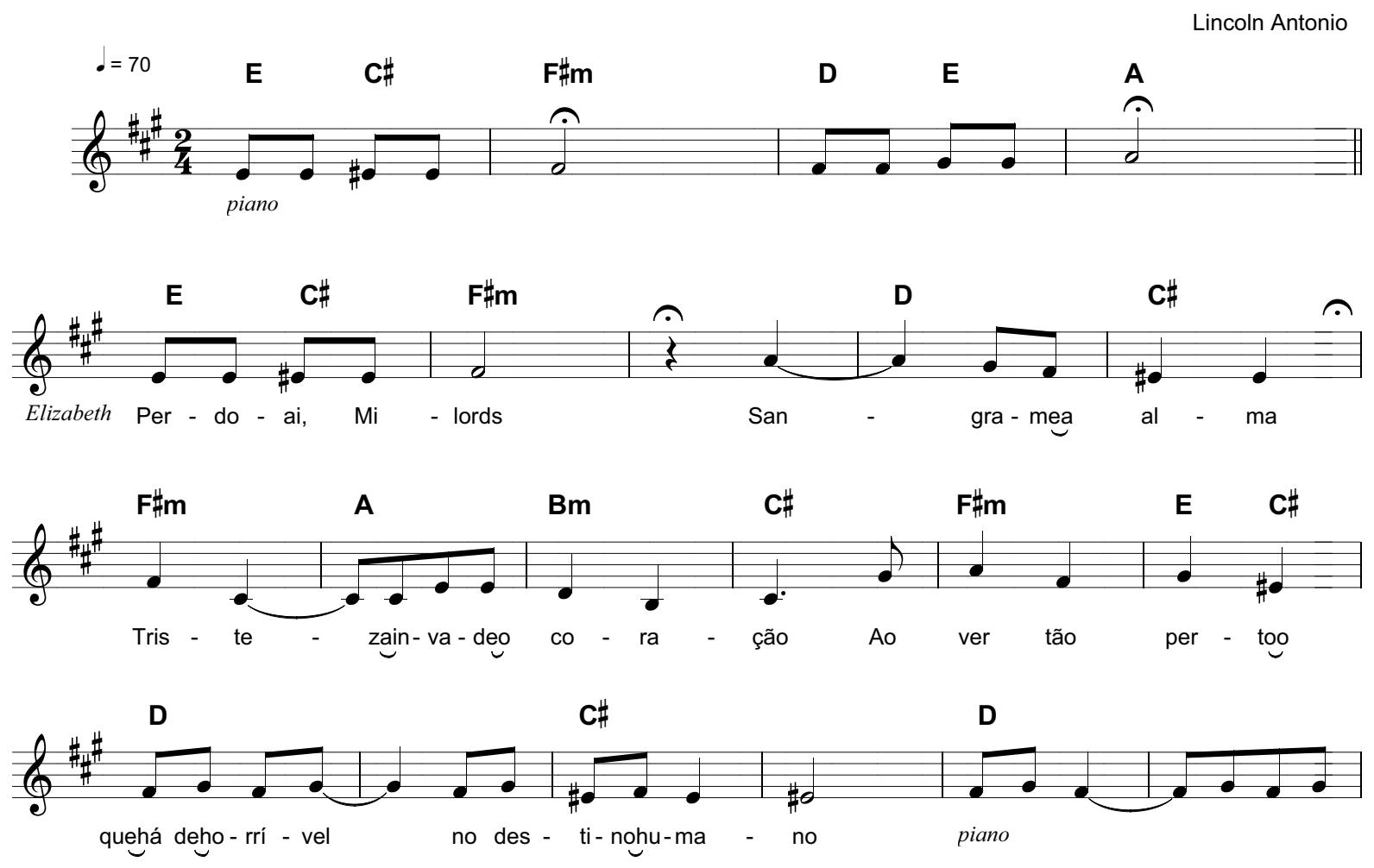

$\oplus$
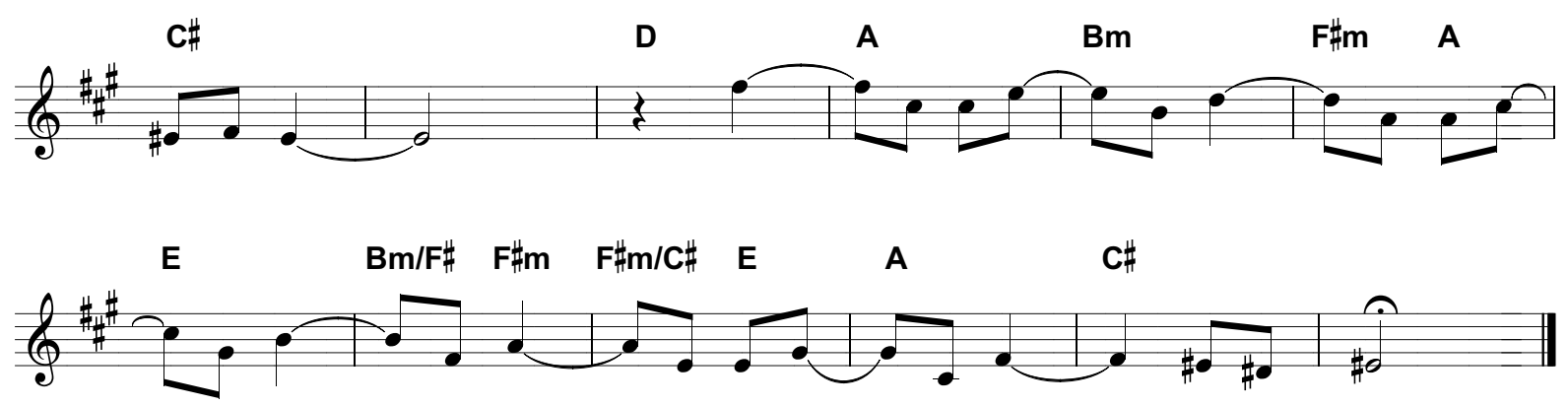

180 


\section{AFÃ DA LIBERDADE}

Lincoln Antonio
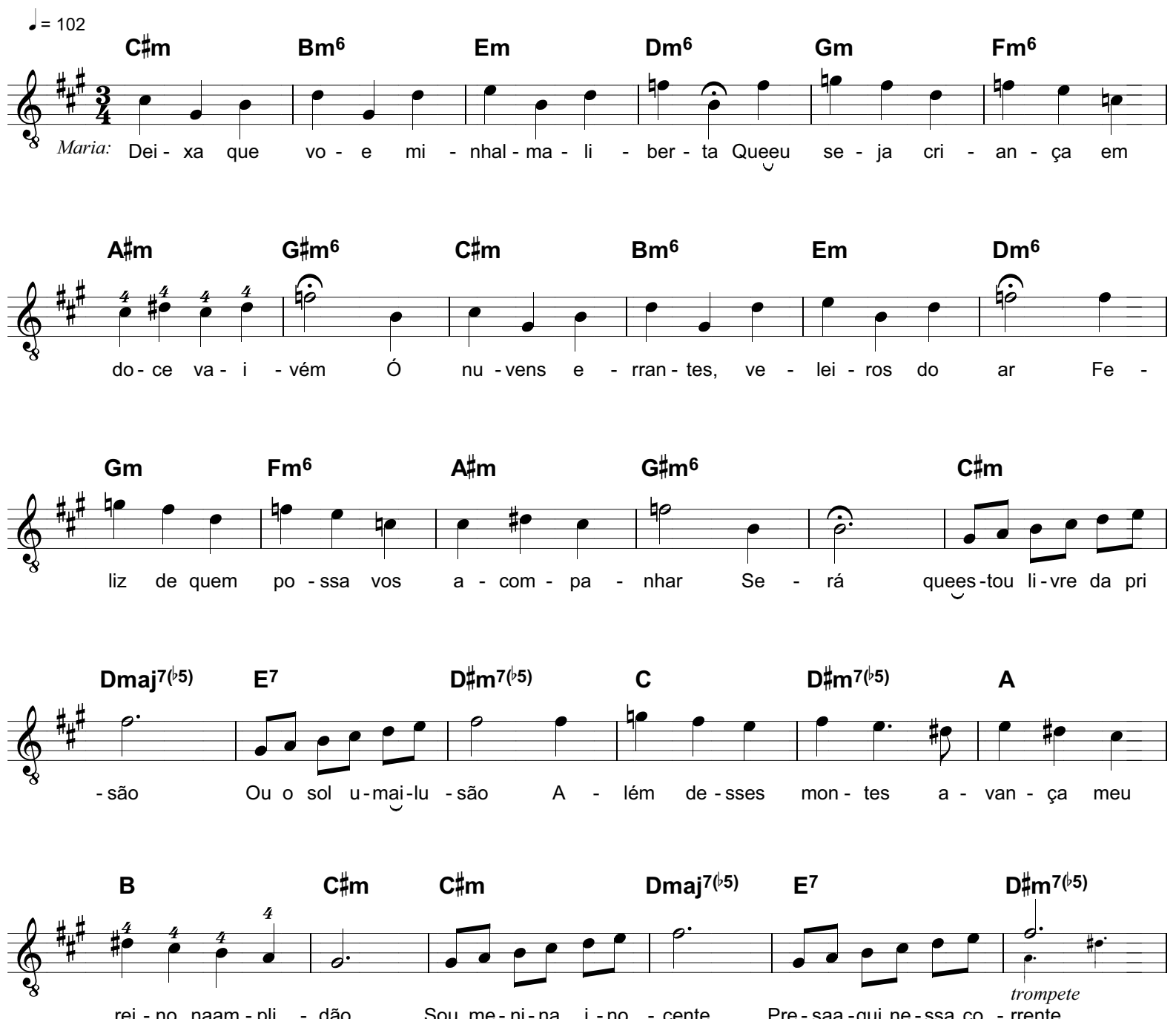

rei - no naam-pli - dão Sou me-ni-na i -no - cente Pre-saa-qui ne-ssa co - rrente
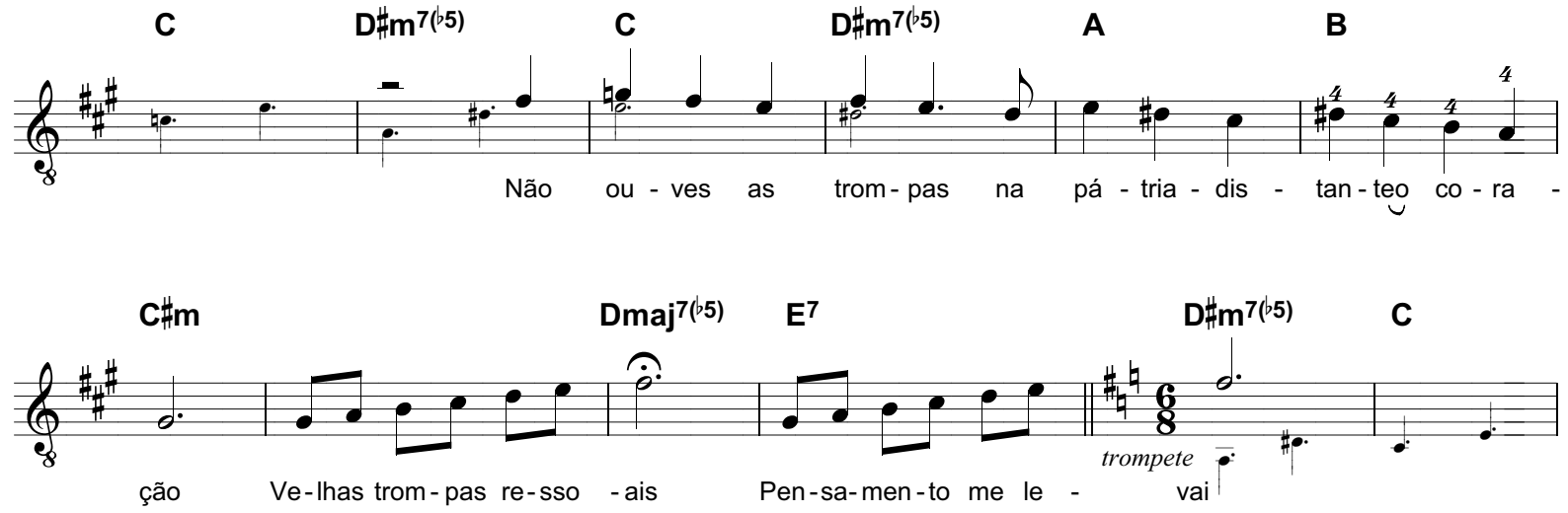
CANÇAO FINAL DE ELIZABETH

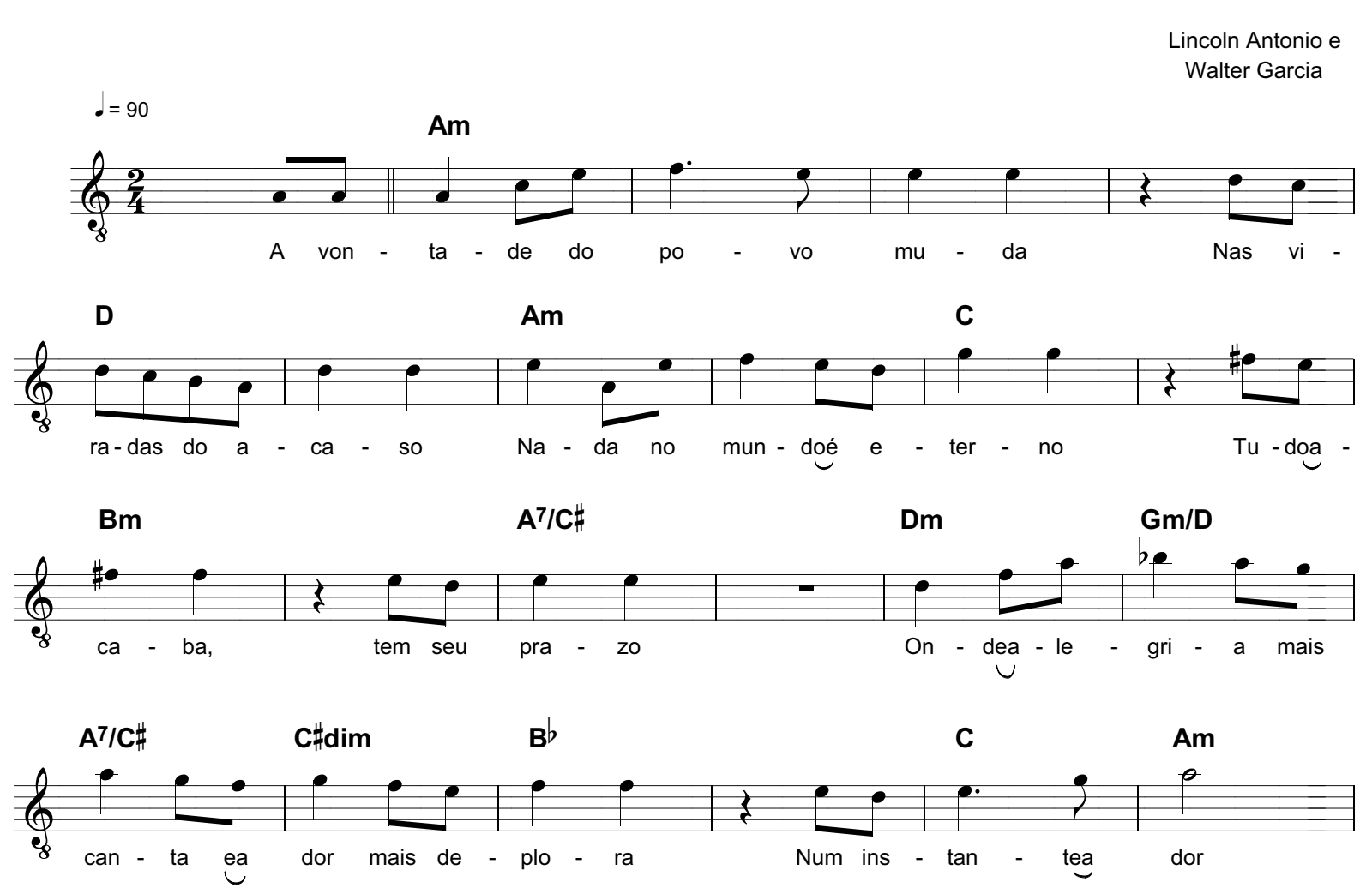

$-$
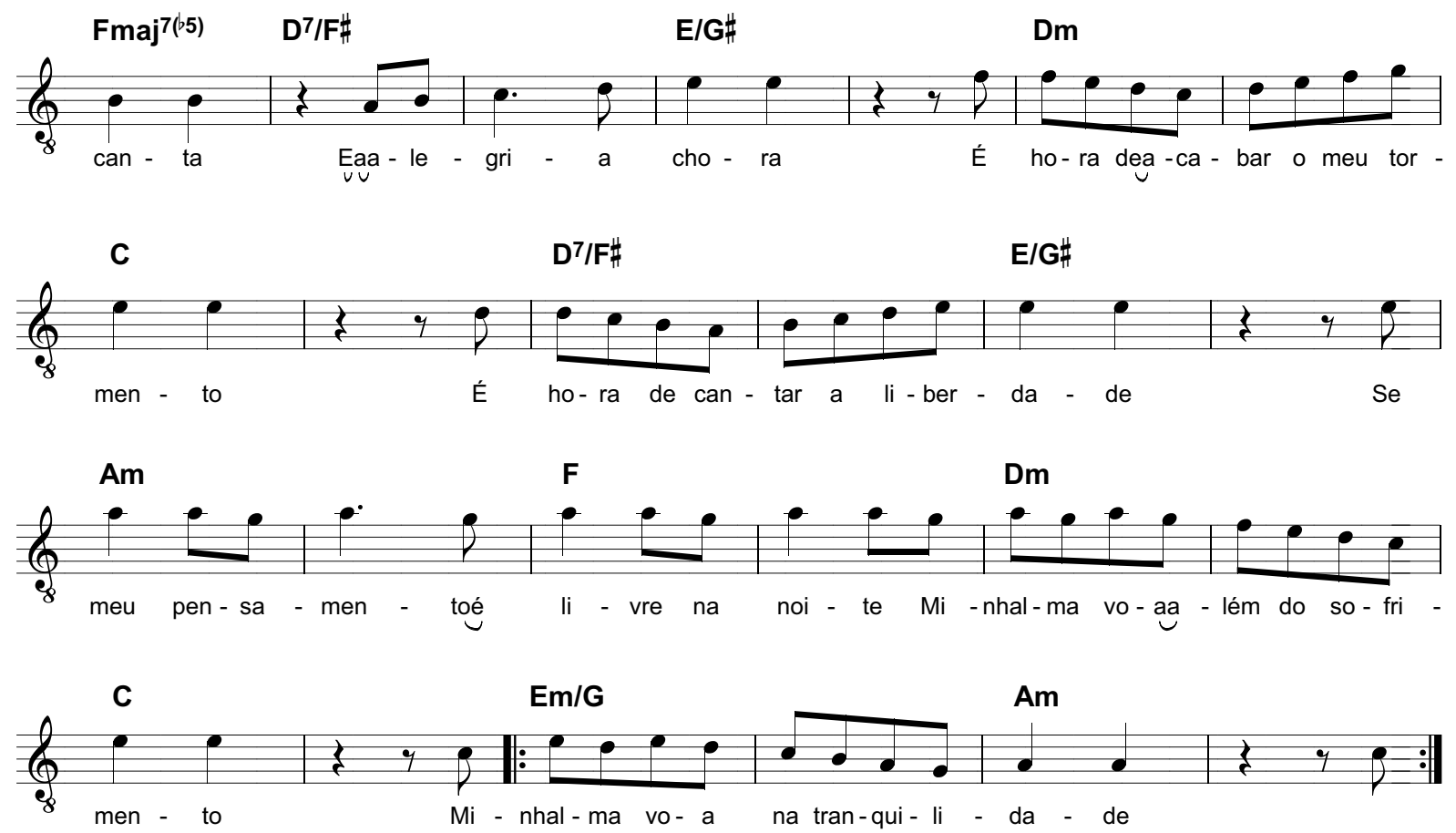

182 


\section{CANÇÃO FINAL DE MARIA}
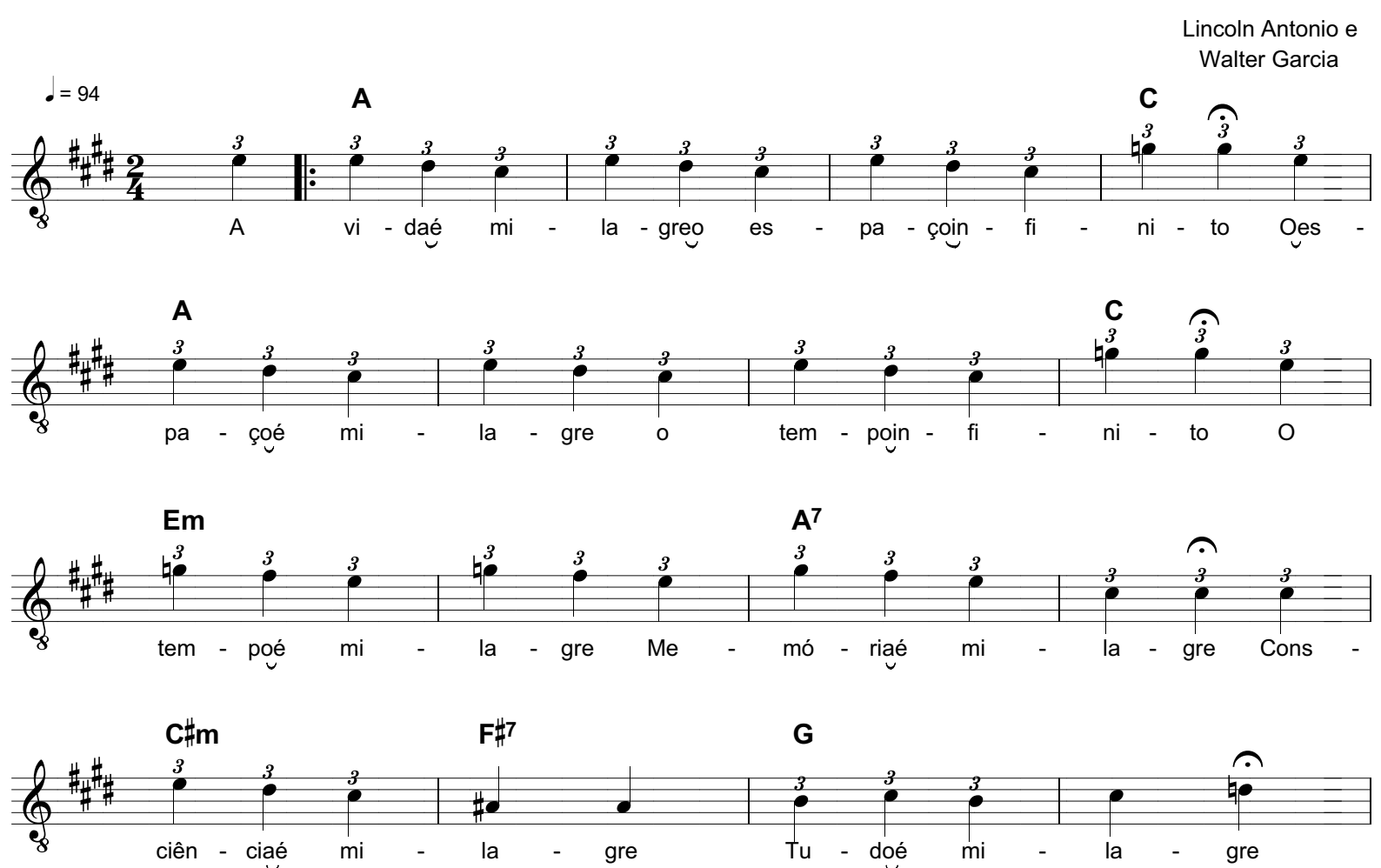

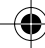
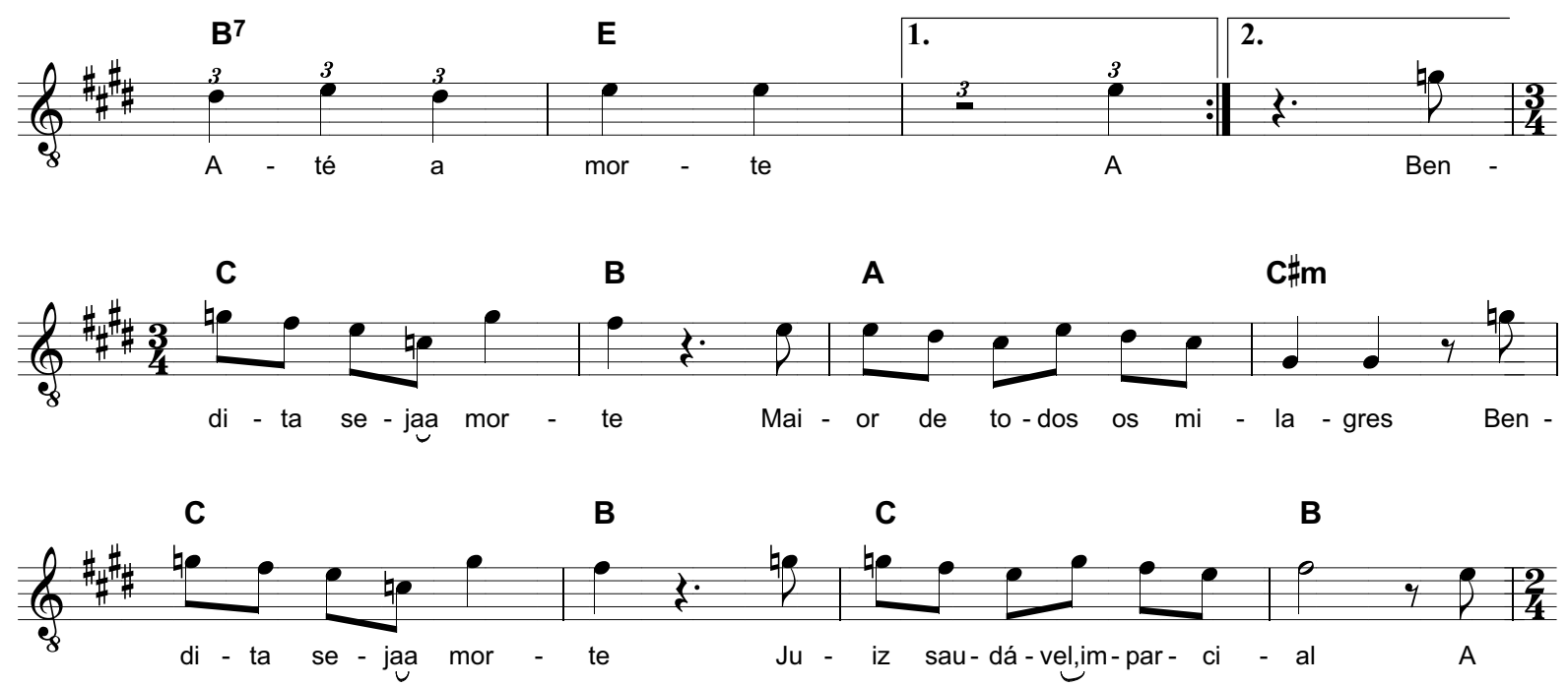
Direção

Cibele Forjaz

Dramaturgia

Isabel Teixeira, Georgette Fadel e Cibele Forjaz

Elenco

Georgette Fadel e Isabel Teixeira

Cenografia e Figurinos

Simone Mina

Luz e operação

Alessandra Domingues

Direção Musical

Lincoln Antonio

Preparação Corporal

Tica Lemos

Direção de Cena

Elisete Jeremias

Assistência de Direção

Luaa Gabanini

Estagiária de direção

Paula Bellaguarda

Assistentes de cenografia e objetos

Carolina Bertier e Patricia Brito

Assistente de figurinos

Patricia Brito

Assistente de cenografia - $1^{a}$ Fase

Vanessa Poitena 
Costureira

Judite de Lima

Bordados

Mariana Lombardo

Visagismo

Emerson Murad

Assistente de visagismo

Anderson Bbatista

Marcenaria

Divaldo Tomé da Silva

Cenotécnico

Erik Klaus

Pintores

Edson Aureliano Pereira

e Emerson Rodrigues da Mata

Assistente de Luz e operação

Mauricio Shirakawa

Músicas

Lincoln Antonio, Manuel Pessoa,

Walter Garcia e John Dowland

Canção "Leve, Meu Coração"

Celso Sim

Voz

Celso Sim e Maria Alice Vergueiro

Piano

Manuel Pessoa

Gravado no Estúdio Outra Margem,

por Paulo Lepetit

Historiador

Rodrigo Bonciani

Direção de arte

Simone Mina 
Imagens (vídeo)

Roberto Setton, Alessandra Domingues

e Luaa Gabanini

Fotos

Roberto Setton

Programação Visual

Fernando Bononi

Estagiário de Programação Visual

Gabriel Satyahari

Assessoria de Imprensa

Frederico de Paula

Produção Executiva - 1a Fase

Mariana Trench

Produção Executiva

Carolina Flor Ga Azcuaga

Direção de Produção

Henrique Mariano

Idealização do Projeto Isabel Teixeira 